\title{
Estudo preliminar de um dicionário português-tupi do período pombalino ${ }^{1}$
}

\author{
Cândida Barros \\ Museu Emílio Goeldi \\ Antônio Luis Salim Lessa \\ PCI-MCT/Museu Emílio Goeldi
}

\section{Abstract}

A Portuguese-Tupi dictionary prepared in Belem in 1771 is analysed in the context of the linguistic policy of Pombal's government in Amazonia, and is compared to Tupi vocabularies compiled in the Jesuit period. By these two means, we will examine whether the Jesuits continued to serve as a reference during the Pombal period for the evangelisation policy in the colony and for the descriptive model of Tupi. 


\section{OBJETIVOS}

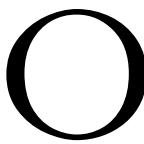

trabalho gira em torno ao manuscrito Diccionario da lingua geral do Brasil que se falla em todas as villas, lugares e aldeas deste vastissimo Estado, escrito em Belém, em 1771, período em que estava proibido pelo Diretório dos Índios o uso da língua tupi em favor do português na Amazônia. Duas questões serão tratadas sobre essa obra: uma delas é contextualizá-la no cenário sociolingüístico da Amazônia e a outra é compará-la com outros dicionários tupi do período jesuítico.

A primeira questão nos levará a descrever a política lingüística de dois agentes coloniais na região amazônica: a administração e a Igreja. A posição da administração pombalina será observada no Diretório dos Índios e em cartas de Francisco Xavier de Mendonça Furtado, irmão de Pombal e governador do Grão-Pará entre 1751 e 1759. A posição lingüística da Igreja na Amazônia no período pombalino será analisada em três documentos: a) no relato do Bispo do Pará, João de São José Queiroz, sobre sua visita paroquial na região entre 1761-1763; b) na defesa do Padre Rosário perante a Inquisição, quando acusado de evangelizar na língua tupi (SILVA, 1993); c) no próprio dicionário de 1771. Neste último caso, queremos saber se o léxico cristão contido na obra tem similaridade com aquele usado pelos jesuítas.

A segunda questão nos levará a comparar o dicionário tupi de 1771 com outras obras deste gênero, pertencentes ao período jesuítico, para verificar se houve continuidade em relação à técnica de dicionarização. Compararemos a forma como eram criadas ou ordenadas as entradas nessas obras, como se organizavam as informações gramaticais e semânticas e como se tratava da variação no interior dos verbetes. 
Nesses dois tópicos, uma pergunta subjacente é se os jesuítas, expulsos da Amazônia por Pombal em 1759, continuaram a ser referência na condução da política de evangelização e na produção de dicionários tupi durante o período pombalino.

Na conclusão, compararemos a política lingüística pombalina na Amazônia com algumas das medidas dirigidas a Goa na mesma época. Verificaremos contrastes e similitudes entre as duas políticas, comparando as posições de um administrador que exerceu funções nas duas colônias.

\section{POLÍTICAS LINGÜÍSTICAS DAS INSTITUIÇÕES COLONIAIS NA AMAZÓNIA NO PERÍODO POMBALINO}

\subsection{A posição da administração pombalina em relação a qual língua usar na evangelização}

O Diretório dos Índios de 1757 foi o principal instrumento do governo português para transformar o espaço das missões religiosas em vilas. Essa legislação transferia o poder dos jesuítas para os diretores, que passavam a ter o controle da mão-de-obra indígena. Sua vigência se estendeu até 1798, quando foi abolida.

No plano lingüístico, o Diretório continha um parágrafo (n.․ 6) que defendia o uso do português na colonização, baseado na máxima de que todo Império deveria falar a língua dos seus Príncipes. A defesa do português como a "língua do príncipe" no Diretório se opunha à longa trajetória do conceito de língua "vernácula" (ou "vulgar") da Igreja tridentina que conduzia a política lingüística a ser usada na evangelização.

Um outro documento que revela a posição da administração pombalina a respeito da língua geral são as cartas oficiais do governador Mendonça Furtado a seu irmão, o Marquês de Pombal, escritas entre 1751 e 1759 (MENDONÇA, 1963). O governador relata suas discussões com os missionários sobre em que língua evangelizar. Estes se diziam obrigados a pregar nas línguas nativas por bulas papais. O governador, por sua vez, respondia que as bulas 
não se aplicavam no caso da Amazônia, tendo em vista que os dois grupos, índios e portugueses, abandonavam suas línguas para falar uma terceira.

[...] perguntando eu a alguns [missionários] para que era este trabalho [de aprender a língua geral], me responderam que eram a isso obrigados como missionários, porque assim o mandava um Breve de Alexandre $7^{\circ}$ [papa entre 1655-1667]; ao que lhes respondi que o Breve era para os missionários que iam pregar o evangelho às regiões aonde era preciso estabelecer-se e falar a língua do país para poderem fazer fruto com a sua missão, mas não no sistema presente, em que aos mestres e aos discípulos lhes era preciso, para se entenderem, largar cada um a língua materna para se comunicarem em uma gíria inventada para confusão e total separação dos homens e em notório prejuízo da sociedade humana. (MENDONÇA, 1963, p. 67)

\subsection{A posição da Igreja em relação à língua de evangelização no período pombalino}

\subsubsection{Visitas dos bispos}

Os relatos das visitas dos bispos são textos adequados para se conhecer a posição da Igreja no período pombalino em relação a qual língua usar na evangelização dos índios. As visitas eram mecanismos de fiscalização dos costumes instaurados pela Igreja tridentina sobre os fiéis e representavam uma vitória da política pombalina, pois, durante o tempo dos jesuítas, estes não aceitavam que os bispos incluíssem as suas missões nas visitas.

Nos relatos das visitas do bispo São José Queiroz, realizadas entre 1761 e 1763, menciona-se a presença da figura do intérprete religioso - padres - acompanhando a visita do Bispo e tendo atuação nas atividades religiosas (QUEIROZ, 1961). A confissão, a explicação do evangelho e o batismo continuavam sendo feitos em língua geral.

A evangelização dos índios não-tupi continuava a ser feita em língua geral, ao estilo dos jesuítas (QUEIROZ, 1961, p. 172). Um sinal da manutenção dessa prática foi a escolha de padres com conhecimento 
do tupi para a região do Rio Negro, a qual se sabe ter sido ocupada no período pré-colonial por grupos não-tupi, como tukano e aruak (GUZMÁN, s.d.). Entre os religiosos que foram enviados para a Capitania do Rio Negro estava o Padre Noronha (1727-1794). Nativo do Pará, ele tinha sido aluno dos jesuítas e era ao seu tempo um dos membros do clero secular mais habilitado em tupi. Padre Noronha foi vigário geral e visitador naquela região por cerca de 14 anos. Outro religioso que atuou ali foi o Padre Manuel das Neves, um jesuíta que havia sido expulso da ordem e se tornou padre secular. Os dois padres indicam a permanência de religiosos bilíngües, na região, familiarizados com a evangelização dos jesuítas.

\subsubsection{Inquisição}

O texto "Questões Apolegéticas enunciadas e dirigidas a mostrar que em nada peca o pároco que na língua vulgar dos índios os instrui”, do Padre Manuel da Penha do Rosário, é a versão em português, provavelmente datada de 1773 , de um documento em latim entregue ao Inquisidor Giraldo José de Abranches.

A defesa do padre Rosário junto à Inquisição está fundamentada no conceito de língua vernácula do Concílio de Trento. Ao longo do documento, organizado em forma de pergunta e resposta, o autor indaga de forma sucessiva se um pároco que prega na língua vernácula peca diante de Deus, se vai contra a Igreja Romana, contra o Bispo ou contra o Rei. A todos responde que não, baseado na determinação de Trento de se pregar na língua vulgar.

Ao longo de sua defesa, Padre Rosário documenta a postura contraditória entre o discurso do Diretório e o cotidiano nas missões. Segundo ele, os diretores, que pela legislação pombalina deveriam promover o uso do português, usavam da língua geral na comunicação com os índios.

Um dos argumentos de Rosário na sua defesa perante a Inquisição era que não havia alvarás ou bandos publicados em praças proibindo os catecismos tupi e obrigando que estes fossem 
queimados. De acordo com Rosário, as paróquias ainda conservavam o catecismo em tupi do período anterior.

Rosário foi inocentado da acusação pelo Inquisidor Dom Giraldo José Abranches e nomeado para novas paróquias (SILVA, 1993). Neste caso, o conceito de língua vernácula se sobrepunha, na Amazônia, ao conceito de "língua do príncipe" defendido no Diretório.

\subsection{Comparação do léxico religioso no dicionário de 1771 com uma obra jesuítica}

Para verificar a informação do Padre Rosário de que os catecismos jesuíticos ainda eram usados nas paróquias dos índios, comparamos o léxico religioso do dicionário de 1771 com o de 1750, de forma a verificar se a obra pombalina seguia as mesmas traduções usadas pelos jesuítas.

Das 123 entradas compartilhadas entre os dicionários de 1771 e 1750, cerca de 85 empregam a mesma raiz tupi na tradução dos conceitos cristãos, ainda que possam apresentar diferenças ortográficas ou dialetais. Apenas em 28 verbetes os dicionários divergem na tradução em tupi ao empregarem radicais distintos. Esses casos de divergência na tradução do léxico cristão nas duas obras, quando comparados com a forma empregada no catecismo de Filipe Bettendorff (1687), revelam que, em alguns itens, a obra do período pombalino estava mais próxima do uso desse catecismo jesuítico do que o dicionário de 1750. 


\section{QUADRO 1}

Comparação de alguns itens lexicais do campo religioso entre dois dicionários e um catecismo tupi

\begin{tabular}{|l|l|l|l|l|}
\hline \multicolumn{2}{|c|}{ Dicionário de 1750 } & \multicolumn{2}{|c|}{ Dicionário de 1771 } & \multicolumn{1}{c|}{$\begin{array}{c}\text { Catecismo de } \\
\text { Bettendorff (1687) }\end{array}$} \\
\hline $\begin{array}{l}\text { Artigos da } \\
\text { fé }\end{array}$ & $\begin{array}{l}\text { Santa Madre } \\
\text { Igreja recó } \\
\text { rerobiaçára } \\
\text { fé }\end{array}$ & $\begin{array}{l}\text { Artigos da } \\
\text { Adamdé remi } \\
\text { robiá rama. }\end{array}$ & $\begin{array}{l}\text { Os artigos da fé são } \\
\text { quatorze. Catorze acẽ } \\
\text { remierobiarâma } \\
\text { (Bettendorff, 7) }\end{array}$ \\
\hline $\begin{array}{l}\text { Adam } \\
\text { Páscó Paya de }\end{array}$ & Adam & $\begin{array}{l}\text { Jandé Pay } \\
\text { ypy. } \\
\text { Ace Paý } \\
\text { ypy. }\end{array}$ & $\begin{array}{l}\text { Nosso primeiro pay Adão } \\
\text { Ace rûbypy Adã } \\
\text { (Bettendorff, 39); Iande } \\
\text { rûbypy Adam } \\
\text { (Bettendorff, 46) }\end{array}$ \\
\hline
\end{tabular}

Na comparação entre os dicionários de 1771 e 1750, verificouse que o primeiro é mais extenso no campo religioso. Entre os 6.877 verbetes da obra de 1771, levantamos cerca de 248 entradas que comporiam o léxico especializado da evangelização. Em número absoluto, o dicionário contemporâneo ao Diretório possui mais entradas para este campo semântico do que o dicionário de 1750, contemporâneo à presença dos jesuítas (189 verbetes). Esse resultado é um indício de que o autor e seus possíveis leitores fossem do mundo eclesiástico, substitutos dos jesuítas nas antigas missões.

\section{COMPARAÇÃO ENTRE OS DICIONÁRIOS PORTUGUÊS-TUPI}

\subsection{Localização geográfica, temporal e institucional dos dicionários}

Foram coletados sete dicionários português-tupi coloniais. Seis deles serão considerados como anteriores à expulsão dos jesuítas, tendo circulado, portanto, em um contexto no qual a Companhia de Jesus tinha a hegemonia na produção de obras lingüísticas. A obra de 1771, por outro lado, foi contemporânea ao governo do Marquês de Pombal. 
Os dicionários são os seguintes:

a) Vocabulário da língua brasílica, 1622, Piratininga (SP) - é o texto mais antigo do conjunto e o único proveniente das missões jesuíticas do Sul. Possui 7.306 verbetes. Seu original pertence à Biblioteca Mário de Andrade. A edição utilizada na comparação foi transcrita e impressa por Ayrosa, em 1938.

b) Caderno da língua, do Padre Arronches, 1739 - é o único que contém autoria. Por meio dela, ficamos sabendo a origem franciscana da obra e a sua localização geográfica no Norte. Padre Arronches morreu em 1759, em Gurupá (Baixo Amazonas, Pará) (Arquivo 2002, vol.1, p. 311). A obra contém 3.881 verbetes. A edição utilizada no trabalho foi transcrita e impressa por Ayrosa (1937).

c) [Vocabulário], [1740-1757] - este dicionário não possui data precisa, mas se encontra em um códice junto com outros documentos datados nessa faixa temporal. Quanto à localização geográfica, a capa do códice menciona que ele pertencia à fazenda jesuítica de Gilboé, em 1757, localizada no rio Tocantins. O dicionário consta de 3.384 verbetes e pertence a British Library (Ayrosa, 1951).

d) Dicionário da língua geral do Brazil [1750, Pará] - a data e a referência geográfica se encontram no final do códice e não no documento propriamente dito. Esse códice contém ainda gramática, orações, diálogos de doutrina e confessionário. O dicionário contém 3.604 verbetes. Pertence à Biblioteca da Universidade de Coimbra.

e) [Vocabulário] [1751, Pará] - este códice tem o mesmo conteúdo que o de 1750, podendo ser uma reprodução modificada daquele, feita um ano mais tarde. Também menciona o Pará e a data de 1751 no mesmo contexto que a obra anterior, no interior de um comentário sobre a validade de uma bula papal entre os índios na região. No tocante ao dicionário desse códice, ele é mais extenso que o de 1750 , pois apresenta 4.190 verbetes, um acréscimo de 486 verbetes. 
f) Prosódia, [<1757] - não temos data, nem procedência institucional e geográfica explicitadas na obra. Porém, a menção à Mortigura - nome pré-pombalino de uma missão jesuítica -, no interior de um verbete, indicaria que o texto é anterior a 1757 , data do Diretório. A partir de Pombal, Mortigura passou a se chamar Vila do Conde. O dicionário teria circulado nas missões do Norte (falase também do Marajó) e teria sido elaborado por jesuítas ao incluírem o nome de sua missão mais antiga. Mortigura foi fundada em 1653 por Antônio Vieira (LEITE, 1938, vol.3, p. 299).

g) Diccionario da lingua geral do Brasil que se falla em todas as villas, lugares e aldeas deste vastissimo Estado, 1771, Cidade do Pará (Belém) - este documento pertence à Biblioteca da Universidade de Coimbra (ms.81). É o único dicionário em que se declara explicitamente a data e o local da sua produção. Não há procedência institucional, mas, pela extensão do léxico religioso, deve ter circulado entre párocos. A obra está acompanhada de uma gramática tupi com as regras de conjugação verbal. Essa seção segue o modelo das obras jesuíticas ao escolher o verbo juca (matar) como exemplo.

Este não é a único dicionário do período pombalino. Há um outro de 1795, o primeiro a ser impresso, mas ele não será contemplado na presente análise. Como essas obras possuem títulos parecidos, a forma de identificação dos dicionários ao longo do trabalho será por meio das datas supostas ou validadas.

\subsection{Comparação das obras segundo as técnicas de dicionários}

O objetivo da análise será comparar os dicionários segundo os estilos adotados em cada um relativamente à forma de criar e organizar as entradas e à forma de organizar o interior dos verbetes. Estas técnicas de dicionarização serão definidas como convenções gráficas de caráter cultural que se diferenciariam por época e por grupos. A identificação das técnicas usadas na obra de 1771 será realizada de forma comparativa com os demais dicionários tupi do corpus. 
Nas questões relacionadas à ordenação dos verbetes, seguiremos as sugestões de Dieter Messner (s.d.) de se enfocarem as entradas em português dessas obras e compará-las com os dicionários portugueses antigos (Bento Pereira e Bluteau). Em relação à analise do interior dos verbetes, tomaremos como ponto de partida o trabalho de José Nunes sobre a história dos dicionários tupi, no qual ele compara a estrutura dos verbetes dessas obras no que concerne às informações gramaticais e propõe um quadro das filiações entre elas (NUNES, 1996).

Messner tem mostrado que os autores das obras coloniais tomavam os dicionários portugueses como roteiro para estabelecer as entradas e como modelo para definir convenções na forma de organizar a obra. Assim, surge para a historiografia lingüística a tarefa de averiguar quais são as fontes portuguesas que os missionários consultaram ao elaborar as entradas das obras em tupi.

O trabalho de José Nunes sobre os dicionários tupi coloniais será importante para se observar a organização interna dos verbetes. A partir da seleção de uma letra comum entre as obras, o autor fez comparações sistemáticas, procurando observar os tipos de informação contidos nos verbetes e compará-los com aqueles presentes na gramática de Anchieta. Utilizaremos o mesmo recurso de selecionar uma letra em comum nos dicionários para os primeiros exercícios de análise e descrição do conteúdo dos verbetes.

\subsubsection{Influências de Bento Pereira nos dicionários tupi}

Procuramos observar se os traços identificados por Messner como específicos do dicionário de Bento Pereira se encontram na obra de 1771. A escolha de Bento Pereira como representante de um dicionário jesuítico português se deve a sua ampla circulação, do século XVII até o XVIII, quando foi proibido por Pombal.

Messner considera como específicas de Bento Pereira as seguintes técnicas de dicionarização:

a) Início do dicionário por uma série de sintagmas preposicionais 
Bento Pereira começa sua obra com cerca de 29 expressões preposicionadas do tipo "a falsa fé", "a boca da noite", "a formiga", etc., e não por palavras como "aba". Encontramos três obras que seguem o modelo de Pereira: 1750, 1751, <1757. As de 1739, [1740] e 1771 não se iniciam por tais expressões.

b) Ordenamento alfabético dos verbetes

Uma diferença entre Bento Pereira e Bluteau está na forma de ordenamento das palavras começadas por AC (Messner). Pereira ordenava foneticamente: "aca" e "aco" vinham juntas e "ace" e "aci" eram postas em seguida. Com Bluteau, estabeleceu-se a ordem alfabética canônica.

Entre os dicionários tupi, o de 1771 segue o estilo de Bento Pereira na forma de ordenar a obra em relação à serie de AC (vejase o Quadro 2), tal como os de 1750 e 1751. É difícil observar com segurança esse fato do ordenamento em todos os dicionários, pois parte do material que usamos foram versões impressas, que podem ter sido reordenadas pelo editor.

QUADRO 2

Forma de ordenar a seqüência AC em alguns dicionários

\begin{tabular}{|c|c|c|}
\hline Bento Pereira & Dicionário de 1750 & Dicionário de 1771 \\
\hline Aca & Aca & Aca \\
\hline AcO & Aco & Ach \\
\hline Acl & Acl & Aça \\
\hline Acq & Acq & Aco \\
\hline Acr & Acr & Acl \\
\hline Act & Act & Acq \\
\hline Acu & Acu & Acr \\
\hline Aça & Ace & Ace \\
\hline Ace & Aci & Aci \\
\hline Aci & AçO & AçO \\
\hline AçO & Açu & Açu \\
\hline Açu & Ach & Acu \\
\hline Ach & -- & Act \\
\hline & & \\
\hline
\end{tabular}


No entanto, um aspecto peculiar do ordenamento dos dicionários coloniais, ausente dos portugueses, é o ordenamento por critérios semânticos, que rompe a ordem alfabética. Esse fenômeno pode ser observado na introdução de novas palavras nesses dicionários, quando os autores preferem inseri-las próximas a outras de mesmo conteúdo semântico.

QUADRO 3

Exemplo de ordenamento por critério semântico

\begin{tabular}{|c|c|}
\hline $\begin{array}{c}\text { Diccionario da lingua geral } \\
\text { do Brazil (1750) }\end{array}$ & $\begin{array}{c}\text { Diccionario da lingua geral } \\
\text { do Brasil (1771) }\end{array}$ \\
\hline Cantar & Cantar \\
\hline Cantiga & Cantiga \\
\hline-- & Cantaro \\
\hline Cantareira & Cantareira \\
\hline Canto dacaza & Canto dacaza \\
\hline
\end{tabular}

c) Forma de especificar semanticamente os verbos

Por fim, pretendemos testar a hipótese sobre o parentesco entre o dicionário de 1771 e o de Bento Pereira, fazendo um exercício de comparação com um verbete que recebesse várias especificações semânticas na obra de 1771. Procuramos saber se essas especificações surgiram em função do dicionário de Pereira ou em função do tupi. Sendo o dicionário desse autor uma obra bilíngüe, as especificações semânticas nos verbetes eram demandadas pela sua tradução para o latim. Queremos saber quais dessas se conservaram na obra em tupi de 1771.

Um bom exemplo é o verbo alimpar: das seis entradas em Bento Pereira, cinco delas se encontram no dicionário de 1771, além de outras três que não estão nas obras portuguesas, mas se encontram nos dicionários tupi anteriores. Assim, as entradas de alimpar mostraram que, ao mesmo tempo em que Pereira foi usado como roteiro para inclusão de novos verbetes, conservaram-se as acepções contidas nas obras anteriores, como o dicionário de 1622. 
QUADRO 4

Exemplo da forma de subcategorizar os verbos em Bluteau e nos dicionários tupi

\begin{tabular}{|c|c|c|c|c|c|c|c|}
\hline \begin{tabular}{|c|} 
Bento \\
Pereira
\end{tabular} & 1771 & 1751 & 1750 & 1739 & 1740 & {$[<1757]$} & 1622 \\
\hline & & & & Alimpar & Alimpar & Alimpar & Alimpar \\
\hline $\begin{array}{l}\text { Alimpar } \\
\text { lavando }\end{array}$ & $\begin{array}{c}\text { Alimpar } \\
\text { lavando }^{2}\end{array}$ & $\begin{array}{l}\text { Alimpar } \\
\text { lavando }\end{array}$ & $\begin{array}{l}\text { Alimpar } \\
\text { lavando }\end{array}$ & & & & \\
\hline $\begin{array}{c}\text { Alimpar } \\
\text { esfregan- } \\
\text { do }\end{array}$ & $\begin{array}{c}\text { Alimpar } \\
\text { esfregan- } \\
\text { do }\end{array}$ & $\begin{array}{c}\text { Alimpar } \\
\text { esfregan- } \\
\text { do }\end{array}$ & $\begin{array}{c}\text { Alimpar } \\
\text { esfregan- } \\
\text { do }\end{array}$ & & & & \\
\hline $\begin{array}{c}\text { Alimpar } \\
\text { varrendo }\end{array}$ & $\begin{array}{c}\text { Alimpar } \\
\text { varrendo }\end{array}$ & $\begin{array}{c}\text { Alimpar } \\
\text { varrendo }\end{array}$ & $\begin{array}{c}\text { Alimpar } \\
\text { varrendo }\end{array}$ & & & & \\
\hline \multicolumn{8}{|l|}{$\begin{array}{l}\text { Alimpar } \\
\text { sacrifi- } \\
\text { cando }\end{array}$} \\
\hline & $\begin{array}{c}\text { Alimpar } \\
\text { espanan- } \\
\text { do }\end{array}$ & $\begin{array}{c}\text { Alimpar } \\
\text { espanan- } \\
\text { do }\end{array}$ & $\begin{array}{c}\text { Alimpar } \\
\text { espanan- } \\
\text { do }\end{array}$ & & & & $\begin{array}{l}\text { Limpar } \\
\text { de po }\end{array}$ \\
\hline & $\begin{array}{c}\text { Alimpar } \\
\text { desenfer- } \\
\text { rujando }\end{array}$ & $\begin{array}{c}\text { Alimpar } \\
\text { desenfer- } \\
\text { rujando }\end{array}$ & $\begin{array}{c}\text { Alimpar } \\
\text { tirar } \\
\text { ferrugem }\end{array}$ & & $\begin{array}{c}\text { Alimpar } \\
\text { da } \\
\text { ferrugem }\end{array}$ & $\begin{array}{c}\text { Alimpar } \\
\text { da } \\
\text { ferrugem }\end{array}$ & $\begin{array}{c}\text { Limpar } \\
\text { de } \\
\text { ferrugem }\end{array}$ \\
\hline & & $\begin{array}{l}\text { Alimpar } \\
\text { a alma }\end{array}$ & $\begin{array}{l}\text { Alimpar } \\
\text { a alma }\end{array}$ & & & & \\
\hline & $\begin{array}{c}\text { Alimpar } \\
\text { vg. arroz }\end{array}$ & $\begin{array}{c}\text { Alimpar } \\
\text { arroz }\end{array}$ & $\begin{array}{c}\text { Alimpar } \\
\text { arroz }\end{array}$ & $\begin{array}{c}\text { Alimpar } \\
\text { arroz }\end{array}$ & & & \\
\hline & $\begin{array}{l}\text { Alimpar } \\
\text { arvores }\end{array}$ & & & & & & \\
\hline & \begin{tabular}{|c|} 
Alimpar \\
o mato \\
por baixo
\end{tabular} & $\begin{array}{c}\text { Alimpar } \\
\text { o mato } \\
\text { por baixo }\end{array}$ & \begin{tabular}{|c|} 
Alimpar \\
o mato \\
por baixo
\end{tabular} & & & & \\
\hline $\begin{array}{l}\text { Alimpar } \\
\text { de pedras }\end{array}$ & $\begin{array}{c}\text { Alimpar } \\
\text { de pedras }\end{array}$ & $\begin{array}{c}\text { Alimpar } \\
\text { de pedras }\end{array}$ & $\begin{array}{c}\text { Alimpar } \\
\text { de pedras }\end{array}$ & & & & \\
\hline $\begin{array}{l}\text { Alimpar } \\
\text { poindo }\end{array}$ & $\begin{array}{l}\text { Alimpar } \\
\text { poindo }\end{array}$ & $\begin{array}{l}\text { Alimpar } \\
\text { poindo }\end{array}$ & $\begin{array}{l}\text { Alimpar } \\
\text { puindo }\end{array}$ & & & & \\
\hline
\end{tabular}


Apesar de a análise estar restrita a trechos da letra A, a proposta de Dieter Messner (2004) se mostrou interessante, ao permitir uma arqueologia dos dicionários coloniais. Em suma, a obra de 1771 não mantém todos os três traços de Bento Pereira; apenas as obras de 1750 e 1751 os possuiriam.

\section{DIMENSÃO DAS OBRAS}

Acrescentaremos como um traço da organização lexicográfica das obras em tupi o número de verbetes. A idéia de que um dicionário é uma obra acumulativa nos faria pensar que a trajetória da obra em tupi foi sempre em crescente, porém tal não ocorreu. No caso do tupi, o dicionário mais antigo é o maior de todos e, depois, foi sendo reduzido.

Um cotejo quantitativo entre os sete dicionários aponta que o de 1771 é o segundo em tamanho, sendo menor que o de 1622 apenas. Este, por sua vez, é o maior de todos.

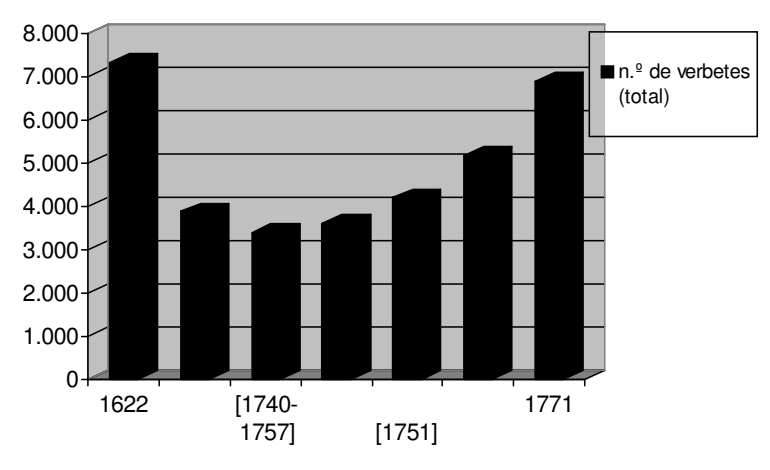

GRÁFICO 1 - Número de verbetes dos dicionários tupi coloniais

O aumento do número de verbetes do dicionário de 1771 em relação ao das obras anteriores apontaria que, no período pombalino, não houve uma queda no repertório do tupi entre os setores coloniais letrados, ou seja, entre aqueles indivíduos que podiam elaborar e/ou consultar um dicionário. 


\subsubsection{Presença ou não de explicações gramaticais e variações nos verbetes}

Neste item, observaremos que tipos de informação estão incluídos nos verbetes dos dicionários e se eles apresentam variação.

\section{a) Explicações gramaticais ou fonéticas}

Observaremos a forma de diálogo entre dois tipos de obras, o dicionário e a gramática, por meio do estudo do tipo de informações gramaticais ou fonéticas contidas nos verbetes.

Nunes (1996) faz uma análise extensa da relação entre a obra de 1622 e a gramática de Anchieta. O dicionário incluía informações sobre o tipo de voz (se é ativo ou neutro) ou sobre o tipo de preposição que se deveria utilizar, questões presentes na Arte de Anchieta.

Os dicionários usados pelas missões na Amazônia mostraram ter diferentes comportamentos nesse aspecto. Os dicionários de [1740] e [<1757] costumam incluir informações sobre o tipo de voz do verbo e as preposições necessárias. Eles também propõem o paradigma de posse nas três pessoas do singular, como neste exemplo:

Beiço, tembê; v.g. xerebe, meos beiços; nderebê, os teos beiços; terceira pessoa, çeébe. (1740, apud FRANÇA, 1859, p. 24)

Dicionários como os de 1771, 1739, 1750 e 1751 se calam sobre essas informações. Em todos os seus 6.788 verbetes, a obra de 1771 inclui informações gramaticais em uma pequena parte dos verbetes. Eis alguns casos:

i) ordem entre os elementos no sintagma no dicionário de 1771

\begin{tabular}{|l|l|}
\hline Agora, ha pouco; & $\begin{array}{l}\text { Amó. Ramó. Estes adverbios se pospoem aos verbos, } \\
\text { a que se ajuntaõ. vg. Ajur amó: ainda agora venho. } \\
\text { Oicó ramó igara recé: Agora ha pouco que está na } \\
\text { canôa. }\end{array}$ \\
\hline Alguma couza. & Amó. Sempre se pospoem ao seu substantivo. \\
\hline
\end{tabular}


ii) processos morfofonêmicos na obra tupi de 1771

\begin{tabular}{|l|l|}
\hline Cerca, ao pé, junto & Tobaké. Na composição - Robáké. \\
\hline Chusma & Teyia. Na composição - Reyia. \\
\hline Corpo & $\begin{array}{l}\text { Teté. Na composição - Reté. O nosso corpo - Jandé } \\
\text { reté. O meu corpo Xe reté. }\end{array}$ \\
\hline
\end{tabular}

\section{b) Presença de variação nos verbetes}

Entendemos por variação lingüística nos dicionários quando, no interior do verbete, seu autor oferece mais de uma maneira de dizer algo. Graficamente, a variação é indicada pelo uso do sinal L (libra), vel ou um ponto entre duas expressões em tupi. O uso desses sinais marcaria a equivalência entre as formas presentes nos verbetes.

A presença ou não da variação em um verbete refletiria a política lingüística assumida pelo autor da obra, pois, em princípio, há sempre mais de uma forma de dizer algo. Quando uma obra como o dicionário registra apenas uma entre tantas, ele acaba estabelecendo uma estandardização.

Os dicionários que fazem parte do corpus da pesquisa apresentam diferentes estilos em relação à variação. Veja-se, no Gráfico 2, o quadro da variação contida nos verbetes da letra B nas sete obras.

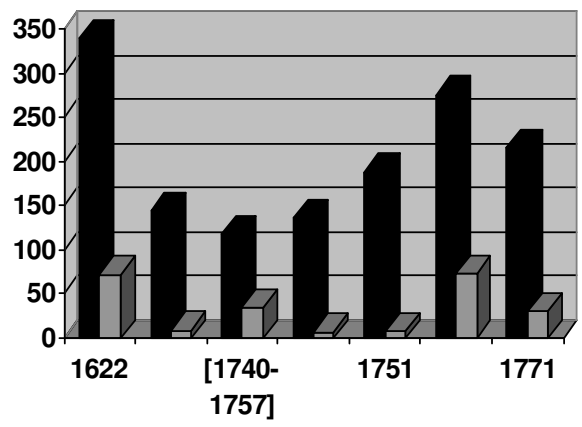

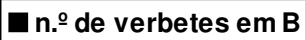

$\square$ n. de verbetes em $B$ com variação

GRÁFICO 2 - Comparação da variação existente nos verbetes da letra B entre os dicionários tupi 
As obras de 1622, [<1757] e [1740-1757] são as que oferecem mais variações no interior dos verbetes. De outro lado, os dicionários de 1750, 1751 e 1739 costumam apresentar apenas uma forma de dizer cada entrada em português. O dicionário de 1771 se apresenta como meio termo entre os dois grupos. Faltaria ainda identificar e diferenciar as variações apresentadas por essas obras.

\subsection{Filiação entre os dicionários português-tupi}

Em geral, analisando os diferentes dicionários tupi pelas suas entradas em português, encontramos pontos em comum entre as obras do período jesuítico e a obra de 1771. Esta pertence à tradição dos dicionários jesuíticos se a compararmos com a obra mais antiga, 1622. Cotejamos as entradas da letra B de 1771 e 1622 e constatamos a existência de 64 itens em comum, cerca de 30 por cento. O fato de ter a mesma entrada em português não elimina a possibilidade de haver diferenças na forma de grafar esta língua, de traduzir para o tupi, ou ainda, na forma de grafar a língua geral. Os autores dos dicionários têm ampla liberdade para modificar tais obras, fato que não se observa em outros gêneros textuais em tupi, como o catecismo.

A primeira questão que se apresentou foi a incorreção de nossa pergunta ao supor uma unidade entre os dicionários contemporâneos aos jesuítas. Não havia um único modelo de verbete entre os dicionários que queríamos comparar com 1771.

Em termos do tipo de organização interna dos verbetes, haveria dois grupos de obras setecentistas usadas no norte. Um grupo estaria composto pelas obras de 1739,1750 e 1751, nas quais os verbetes não fornecem quase nenhuma informação gramatical ou fonética. Por outro lado, as obras de 1740 e < 1757 seguem a tradição do dicionário de 1622, marcada pela inclusão de exemplos, variação e informações gramaticais, como se vê no exemplo seguinte. 


\begin{tabular}{|c|l|l|}
\hline $\mathbf{1 6 2 2}$ & Largar da mão. & Apoir (çuî). Aimõdô. \\
\hline $\mathbf{< 1 7 5 7}$ & Largar da mão. & Apoír. (çüí) \\
\hline$[\mathbf{1 7 4 0 - 1 7 5 7 ]}$ & Largar, demitto & apuir, pede çüí. \\
\hline $\mathbf{1 7 3 9}$ & Largar & poir. \\
\hline $\mathbf{1 7 5 0}$ & Largar & Poir \\
\hline $\mathbf{1 7 5 1}$ & Largar & Poýr \\
\hline $\mathbf{1 7 7 1}$ & Largar & Poire. Moápóc. \\
\hline
\end{tabular}

Em relação ao ordenamento dos verbetes, observamos que os dicionários de 1750 e 1751 apresentam os traços característicos de Bento Pereira (MESSNER, s.d.). A obra de 1771, por seu turno, não conserva todas as características do autor português apontadas por Messner (s.d.), as quais, no entanto, aparecem em outro dicionário pombalino, o de 1795.

\begin{tabular}{|l|c|c|c|c|c|c|}
\hline & $\mathbf{1 7 3 9}$ & $\mathbf{1 7 4 0 - 5 7}$ & $\mathbf{1 7 5 0}$ & $\mathbf{1 7 5 1}$ & $<\mathbf{1 7 5 7}$ & $\mathbf{1 7 7 1}$ \\
\hline $\begin{array}{l}\text { Forma de iniciar } \\
\text { a obra }\end{array}$ & - & + & + & + & + & - \\
\hline $\begin{array}{l}\text { Ordenamento } \\
\text { alfabético }\end{array}$ & - & - & + & + & - & + \\
\hline $\begin{array}{l}\text { Subcategorização } \\
\text { do verbo }\end{array}$ & - & - & + & + & - & + \\
\hline
\end{tabular}

\section{A TÍTULO DE CONCLUSÃO: DIFERENÇAS E SIMILITUDES ENTRE GOA E AMAZÔNIA EM TERMOS DE POLÍTICA LINGÜÍSTICA POMBALINA}

Na primeira parte do trabalho, apontamos as divergências entre a administração pombalina e a Igreja em relação a qual língua se deveria usar na evangelização dos índios. A administração defendia o uso da "língua do príncipe", enquanto a Igreja mantinha, na sua prática diária, o modelo de evangelização jesuítica. Essa continuidade ocorreu pelo uso do mesmo material catequético e pela opção de converter em tupi, mesmo nas regiões onde não havia grupos desta 
família lingüística, como no Rio Negro. Foi entre os religiosos, portanto, que obras como o dicionário de 1771 devem ter circulado.

Na segunda parte do trabalho, a comparação dos dicionários apontou que a obra de 1771 era caudatária daquelas contemporâneas aos jesuítas. Provavelmente, o autor de 1771 teve à sua disposição as obras dos jesuítas. Em particular, ele consultou uma vertente de obras que haviam sido reformadas por técnicas de dicionarização de Bento Pereira, ao mesmo tempo em que desapareciam informações gramaticais ou marcas de diversidade no modo de falar tupi no interior dos verbetes.

Por último, procuramos saber se a contradição existente na Amazônia entre administração e Igreja em relação a que língua usar na evangelização se repetiu em outras colônias portuguesas no período pombalino. Ao ler a obra de Rivara (1858) sobre a história do konkani em Goa, encontramos uma situação distinta à da Amazônia. Na Índia, Pombal não proibiu o uso das línguas nativas em um colégio para religiosos indianos que substituiriam os jesuítas. A administração colonial em Goa procurou substituir as ordens regulares por um clero indiano (LOPES, 1999, p.169). Nesta conjuntura, o argumento de conhecer as línguas de Goa era o principal motivo da administração pombalina para sustentar esta preferência pelo clero nativo. Um exemplo dessa forma de argumentar por parte da administração pombalina é uma carta de 1766 de Mendonça Furtado, ex-governador do Pará e nessa data Secretário de Estado da Marinha e Ultramar, dirigida ao Bispo de Goa.

Entre as ditas providencias lembra aqui a de V.Ex. declarar que na conformidade das regias instruções, expedidas a esse Governo, nas datas de 26 de Março de 1759, e 2 de abril de 1761 devem preferir para as Parochias os Naturaes da terra, e dos de fora os que souberem a língua, porque de outra sorte não podem apascentar ovelhas, cujos balidos não entendem, nem ministrar-lhes pasto desconhecido, do qual de nenhuma sorte podem aproveitar-se. (Carta de Francisco Xavier de Mendonça Furtado ao senhor arcebispo Primaz do Oriente, 1766) (RIVARA, 1858, p. 417) 
Se a carta de Mendonça aponta para políticas diferenciadas, encontramos, entretanto, uma similaridade entre o governo de Pombal em Goa e na Amazônia quanto ao destino das bibliotecas jesuíticas. Nas duas colônias, houve o seqüestro dessas bibliotecas e a sua passagem para a Igreja. Na Amazônia, as bibliotecas jesuíticas foram passadas para o Bispo de Belém em 1761, mesmo ano em que foi feita a transferência em Goa. A doação da livraria dos jesuítas ao bispo estava sob a condição de mantê-la aberta durante as manhãs de todos os dias do ano que não fossem dias de guarda.

No seqüestro da biblioteca jesuítica em Goa, Rivara chama a atenção para o fato de que Pombal havia ordenado que as gramáticas sobre as línguas coloniais dos missionários fossem usadas nos seminários. (RIVARA, 1858, p. 63).

O seqüestro e posterior doação da biblioteca jesuítica para os religiosos e o interesse particular da administração pombalina pelo material lingüístico dos missionários da Companhia de Jesus reforçam a hipótese sobre a continuidade entre o modelo pombalino e o jesuítico na evangelização pela língua tupi e na forma de organizar os dicionários.

\section{NOTAS}

${ }^{1}$ Trabalho apresentado no Segundo Seminário Internacional sobre Lingüística Colonial-Missionária (março de 2004, USP). A pesquisa recebeu apoio do CNPq para sua realização. Agradecemos ao Prof. Dieter Messner a disponibilização de trechos do Dicionário dos Dicionários, assim como de seus comentários. Sheila Rodrigues colaborou na comparação entre os dicionários tupi.

${ }^{2}$ A forma presente no manuscrito deste dicionário é cavando, porém, na tradução em tupi, encontramos a mesma forma empregada nas demais obras para o verbete "alimpar lavando". Assim, interpretamos esse caso como um equívoco do autor do dicionário. 


\section{REFERÊNCIAS BIBLIOGRÁFICAS}

ARQUIVO PÚBLICO DO PARÁ. Catálogo de documentos manuscritos avulsos da Capitania do Pará existentes no Arquivo Histórico Ultramarino de Lisboa. 2002. 3. v.

AYROSA, Plínio. O caderno da língua ou vocabulário portuguez-tupi de frei João Arronches. In: Revista do Museu Paulista 21, 1937.

- Vocabulário da língua brasílica. Manuscrito português-tupi do século XVII, coordenado e prefaciado por Plínio Ayrosa. São Paulo: Departamento de Cultura, 1938.

- Vocabulário português-brasílico. Mss. do século XVIII transcritos e ordenados In: Boletim de Etnografia e Tupi-Guarani 21. São Paulo: Faculdade de Filosofia, Ciências e Letras, 1951.

BETTENDORFF, João Felipe. Compendio da Doutrina Christãa na Lingua Portuguesa e Brasilica. Imprensa Miguel Deslandes, 1687.

DICCIONARIO da lingua geral do Brasil que se falla em todas as villas, lugares e aldeas deste vastissimo Estado. Escrito na Cidade do Pará. 1771. Biblioteca da Universidade de Coimbra - Ms. 81.

DICCIONARIO portuguez e brasiliano, obra necessária aos ministros do altar. Lisboa: Officina Patriarcal, 1795.

FRANÇA, Ernesto Ferreira. Chrestomatbia da lingua brazilica. Leipzig: F.A. Brockhaus, 1859.

GRAMATICA da Lingua Geral do Brazil. Com hum Diccionario dos vocabulos mais uzuaes para a intelligencia da dita lingua. 1750. Biblioteca da Universidade de Coimbra - Ms. 69.

GUZMÁN, Décio de Alencar. Índios misturados, caboclos e curibocas: análise histórica de um processo de mestiçagem, Rio Negro (Brasil), séculos XVIII e XIX, [s.d.].

LEITE, Serafim. História da Companbia de Jesus no Brasil. Rio de Janeiro: Instituto Nacional do Livro, 1938-50. 10. v.

LOPES, Maria de Jesus dos Mártires. Goa Setecentista - Tradição e Modernidade. Universidade Católica Portuguesa, 1999.

MENDONÇA, Marcos Carneiro. A Amazônia na era pombalina-Correspondência inédita do governador e capitão general do Estado do Grão Pará e Maranhão Francisco Xavier de Mendonça Furtado (1751-1759). v.1. Rio de Janeiro: Instituto Histórico e Geográfico Brasileiro, 1963.

MESSNER, Dieter. Anotações aos primeiros dicionários português-tupi, [s.d.]. 
MESSNER, Dieter. Dicionário dos dicionários portugueses. Disponível em: $<$ http://www.sbg.ac.at/rom/people/prof/messner/dddport.htm>. Acesso em: 2004.

NUNES, José Horta. Discurso e instrumentos lingüisticos no Brasil: dos relatos de viajantes aos primeiros dicionários. 1996. Tese (Doutoramento em Lingüística) - Faculdade de Letras, UNICAMP, Campinas.

PROSODIA. Dicionario da língua falada por índios do Brasil. Academia de Ciências de Lisboa, [s.d.].

QUEIROZ, D. Frei João de São José. Visitas Pastorais - Memórias (1761 e 17621763). Rio de Janeiro: Editora Melso, 1961.

RIVARA, Joaquim Heliodoro da Cunha. Ensaio Histórico da língua concani. Nova Goa: Imprensa Nacional, 1858.

SILVA, José Pereira da. Língua vulgar versus a língua portuguesa. A defesa do Pe. Manuel da Penha do Rosário contra a imposição da língua portuguesa aos índios por meio de missionário e párocos. 1773. Introdução, leitura crítica e notas de J.P. da Silva. In: Anais da Biblioteca Nacional 113, 1993. 